\title{
Experimental Study on Performance and Combustion Analysis of a Diesel Engine Fueled with Diesel and Jatropha Oil Blended with Heptane
}

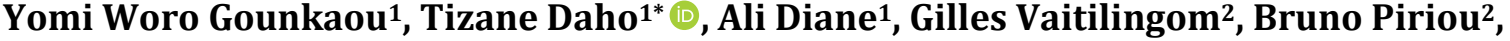 \\ Jeremy Valette ${ }^{2}$, Oumar Sanogo ${ }^{3}$, Antoine Béré ${ }^{1}$
}

${ }^{1}$ Département de Physique, Université Joseph KI-ZERBO, Ouagadougou, Burkina Faso

${ }^{2}$ Biomasse Bois Energie Bioproduits, Montpellier, France

${ }^{3}$ Centre National de la Recherche Scientifique et Technologique, Ouagadougou, Burkina Faso

Email: *tizane_daho@yahoo.fr, ‘tizane.daho@gmail.com

How to cite this paper: Gounkaou, Y.W., Daho, T., Diane, A., Vaitilingom, G., Piriou, B., Valette, J., Sanogo, O. and Béré, A. (2021) Experimental Study on Performance and Combustion Analysis of a Diesel Engine Fueled with Diesel and Jatropha Oil Blended with Heptane. Energy and Power Engineering, 13, 1-16.

https://doi.org/10.4236/epe.2021.131001

Received: November 15, 2020

Accepted: January 5, 2021

Published: January 8, 2021

Copyright $\odot 2021$ by author(s) and Scientific Research Publishing Inc. This work is licensed under the Creative Commons Attribution International License (CC BY 4.0).

http://creativecommons.org/licenses/by/4.0/

\section{(c) (i) Open Access}

\begin{abstract}
This work focuses on blending Jatropha oil with diesel fuel and heptane to improve its physico-chemical characteristics for production of blends and their use as fuel in a diesel engine. The influence of the heptane content was evaluated by comparing the results obtained from the engine (performance and combustion parameters) with those of the diesel fuel and straight Jatropha oil. The results obtained show an improvement in engine performance especially at low loads. Specifically, a reduction in the specific fuel consumption of the engine is obtained when the heptane content in the mixture is around $10 \%$ compared to that obtained with pure Jatropha oil. The best results were obtained with the blend containing $70 \%$ Jatropha oil, $20 \%$ diesel fuel and 10\% heptane (J70G20H10). Overall engine efficiency and exhaust gas temperatures are comparable for all fuels tested. Engine combustion parameters are improved with J70G20H10. The results obtained with J70G20H10 are close to those of the engine operating on diesel fuel. The cyclic dispersion is low with coefficients of variation of the indicated mean effective pressure $\left(\mathrm{COV}_{\text {IMEP }}\right)$ whose values are less than $10 \%$. The lowest values of the $\mathrm{COV}_{\text {IMEP }}$ are obtained with the blend J70G20H10.
\end{abstract}

\section{Keywords}

Diesel Engine, Jatropha Oil, Heptane, Blends, Engine Performance, Cyclic Dispersion 


\section{Introduction}

Energy plays an important role in social and economic development of a country [1]. Indeed, the energy access is an important factor in food and industrial development and in the provision of social services to improve people living conditions. Particularly for sub-Saharan African countries, the poor access to modern energy services is glaring. For example, the electrification rate in this region was about $42.8 \%$ in 2016 [2], compared to some regions of the world (Middle East, North Africa, etc.) where this rate is above $90 \%$. This energy gap affects more the populations in rural areas. Indeed, more than $80 \%$ of the population in these regions has no access to electricity [2]. To overcome this energy gap, renewable energies such as solar, wind, hydro, biomass, etc. are good alternatives. One of these interesting alternatives is the production and use of biofuels, in particular vegetable oils.

Vegetable oils can be produced locally to meet energy needs and they are not subject to the intermittency of the energy source as observed for other sources such as solar, wind etc. Thus, the combustion of vegetable oils in diesel engines has been the subject of many studies [3]-[11]. Most of these studies highlighted that the direct use of vegetable oils in a diesel engine could lead to many problems if certain conditions are not met. The main problems encountered are carbon deposits on certain parts of the engine, power and efficiency decreases, fuel over-consumption, fuel jet pumping and spraying problems, etc. [4] [8] [12] [13]. These problems are related to thermal conditions in the combustion chamber and the physical and chemical nature of vegetable oils (low volatility, fatty acid composition, high viscosity) [3] [5] [14]. Indeed, vegetable oils are mainly made up of fats (triglycerides) at more than $95 \%$ and $5 \%$ of free fatty acids, sterols, waxes, and other minority compounds. These fats are difficult to ignite and they polymerize on the engine cold parts when thermal conditions in the combustion chamber are not established (especially at low loads).

Most of technological solutions (from the literature) to improve the physico-chemical characteristics of vegetable oils (fuel preheating, oil esterification, diesel-oil blends or emulsions of oil and alcohol or water) still present some limits: ineffectiveness to overcome problems encountered, high costs, complex implementation in some areas etc. Recent work on the evaporation of vegetable oils droplets has shown that triglyceride break down into light and flammable volatile materials (alcohols, alkanes, alkenes, etc.) which, when they reach a critical threshold amount, ignite and trigger combustion [7] [14] [15]. Thus the formulation of fuels based on vegetable oils and light compounds such as alkanes can be a good way to overcome some problems observed with straight vegetable oils, specifically at low engine loads. When considering alkanes, heptane appears also like a good cetane number improver that can be used. However, there is few work in the literature on heptane as material to boost the combustion of vegetable oils in diesel engines. So the main objective of this work is to produce mixtures made from Jatropha oil, heptane and diesel fuel, whose combustion in a 
diesel engine gives performance and combustion parameters better to those obtained with straight Jatropha oil and close to those obtained with diesel fuel. It is expected that heptane and diesel will create an important mass of volatile and flammable compounds during the ignition process and improve the whole combustion.

To assess the combustion quality, a detailed analysis of the combustion cycles in the engine (cyclic dispersion) has been carried out. This work is part of a research effort led by the authors to develop sustainable technologies for the use of vegetable oils in specific applications. The emissions and the carbon deposit are expected to be measured in a future paper.

\section{Materials and Methods}

\subsection{Engine Test Bench}

The tests were carried out at "Laboratoire de Physique et de Chimie de l'Environnement" of the Université Joseph KI-ZERBO (Burkina Faso). A Lister diesel engine is installed on a test bench. It is a water-cooled indirect injection diesel engine with a maximum power output of $7.35 \mathrm{~kW}$. It is coupled, using transmission belts, to a generator that produces the electrical current necessary for the diesel engine load. The characteristics of the engine and generator are given in Table 1. The test bench consists of the engine, the current generator, a fuel consumption measurement system, an engine combustion parameter acquisition system and a resistive load bench (consisting of $150 \mathrm{~W}, 500 \mathrm{~W}$ and $1000 \mathrm{~W}$ lamps respectively used to apply an electrical load to the generator). The schematic

Table 1. Engine and generator characteristics.

\begin{tabular}{|c|c|c|}
\hline & Characteristics & Specification \\
\hline \multirow{10}{*}{ Engine } & Type & $\begin{array}{l}\text { Lister, water cooled, indirect injection, } \\
\text { single cylinder }\end{array}$ \\
\hline & Bore $\times$ stroke $(\mathrm{mm})$ & $120 \times 139.7$ \\
\hline & Standard fuel injection pressure & 170 bars \\
\hline & Standard fuel injection timing & $20 \mathrm{CA}$ BTDC \\
\hline & Rated power $(\mathrm{kW})$ & $7.35 \mathrm{~kW}$ \\
\hline & Rated speed ( rpm) & 1000 \\
\hline & Compression ratio & $17: 1$ \\
\hline & Conrod (mm) & 307 \\
\hline & Injection pump & $\mathrm{BOSCH}$ \\
\hline & Type injection & Indirect \\
\hline \multirow{4}{*}{ Generator } & Type & STC \\
\hline & Rated power $(\mathrm{kW})$ & $8 \mathrm{~kW}$ à $1500 \mathrm{rpm}$ \\
\hline & $\operatorname{Cos} \varphi$ & 0.8 \\
\hline & Rated speed (rpm) & 1500 \\
\hline
\end{tabular}


diagram of the experimental set-up is given in Figure 1. For the measurement of the cylinder pressure, a KISTLER piezoelectric sensor type 6125C11 was used. The signals received from the sensor are amplified by a KISTLER 5011B charge amplifier. For the measurement of the injection pressure, a KISTLER piezoresistive sensor type 4067C3000A2 was used. This sensor is connected to a signal conditioner that amplifies the voltage variations measured by the sensor. The two signals from these sensors are collected by a National instruments NI 9215 acquisition module. Three type $\mathrm{K}$ thermocouples are used to measure the ambient air temperature, exhaust gas temperature and engine lubricating oil temperature. The thermocouples are connected to National instruments NI 9211 module. A KISTLER angle encoder type $2614 \mathrm{C} 11$ is used to clock the signals received from the various sensors with a resolution of 720 points per cycle. LabVIEW is used to record the different signals. The average sample selected is 100 cycles; this number offers a good accuracy for the calculations [16].

\subsection{Test Procedure}

Figure 2 illustrates the procedure used for all tests. The characteristics of diesel fuel and Jatropha oil are given in Table 2.

The overall performances considered in this study are fuel specific consumption, thermal efficiency and exhaust gas temperature. The combustion parameters are ignition delay, rate of heat release and cyclic dispersion.

For the estimation of the fuel ignition delay, the start of combustion was identified with the injection curve and the ignition start of combustion corresponding of the first positive point of curve of heat release rate after the injection of fuel. The heat release rate was determined from Equation (1) [18].

$$
\frac{\mathrm{d} Q}{\mathrm{~d} \theta}=\frac{\gamma}{\gamma-1} P \frac{\mathrm{d} V}{\mathrm{~d} \theta}+\frac{1}{\gamma-1} V \frac{\mathrm{d} P}{\mathrm{~d} \theta}+\frac{\mathrm{d} Q_{\text {wall }}}{\mathrm{d} \theta}
$$

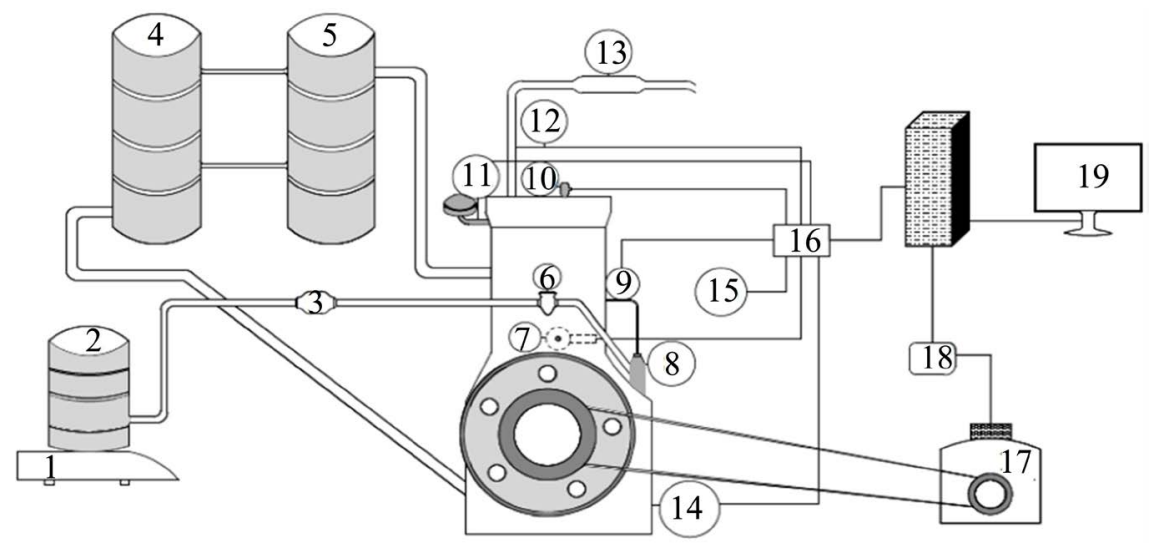

Figure 1. Schematic diagram of the experimental set-up. (1) balance; (2) tank; (3) fuel filter; (4) hot water barrel; (5) cold water barrel; (6) fuel filter; (7) angle encoder; (8) injection pump; (9) injection pressure sensor; (10) cylinder pressure sensor; (11) Intake pressure sensor; (12) Exhaust thermocouple; (13) Exhaust; (14) Lubricating oil thermocouple; (15) Thermocouple for ambient temperature; (16) Acquisition rack; (17) Generator; (18) Power analyzer; (19) Computer 
Table 2. Characteristics of diesel fuel and jatropha oil.

\begin{tabular}{cccc}
\hline Characteristics & Methods & Diesel & Jatropha oil \\
\hline Kinematic viscosity at $40^{\circ} \mathrm{C}(\mathrm{cSt})$ & ASTM D445 & 2.44 & 35.98 \\
Density at $20^{\circ} \mathrm{C}\left(\mathrm{kg} / \mathrm{m}^{3}\right)$ & ASTM D 1298 & 850 & 917 \\
Conradson residue $(\%)[17]$ & ASTM D 189 & 0.1 & 0.8 \\
Lower Heating Value $(\mathrm{kJ} / \mathrm{kg})$ & ASTM D 240 & 42,852 & 36,974 \\
Flash point $\left({ }^{\circ} \mathrm{C}\right)[17]$ & ASTM D 97 & 71 & 229 \\
Cloud point $\left({ }^{\circ} \mathrm{C}\right)$ & ASTM D 97 & -6 & 4
\end{tabular}

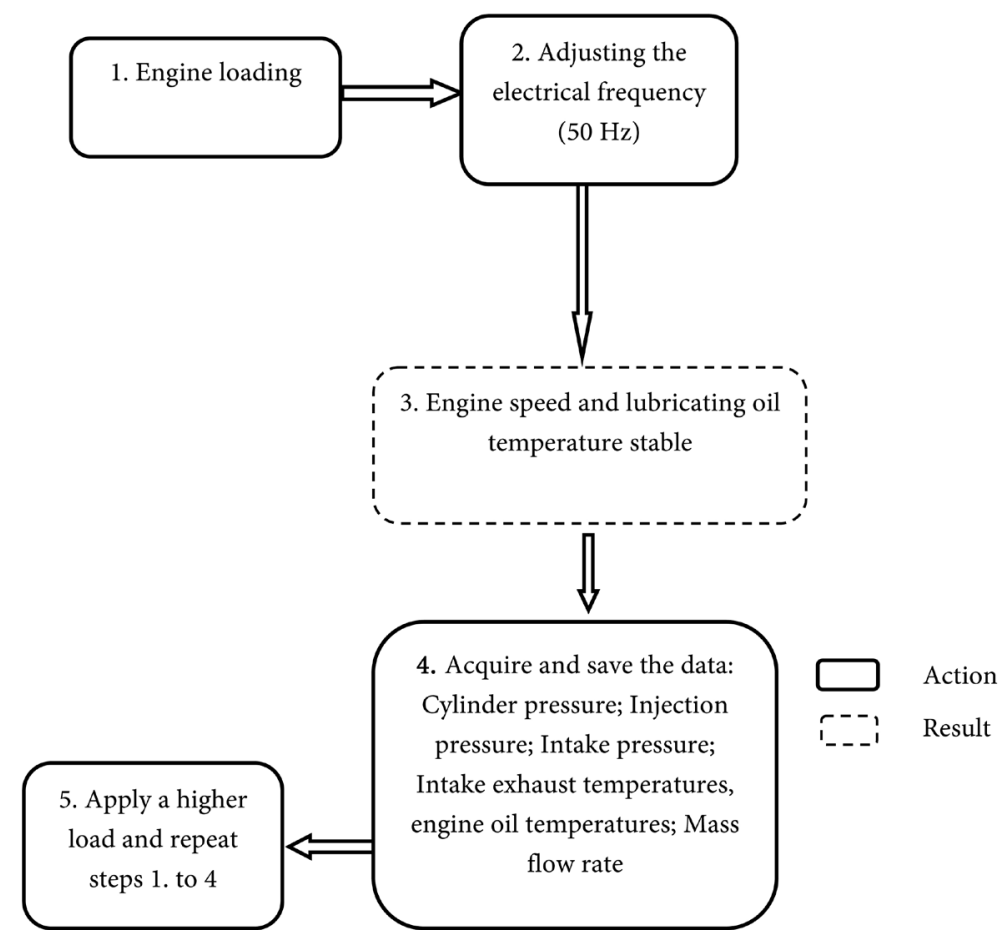

Figure 2. Test procedure.

with $P$ the gas pressures in the cylinder, $V$ the volume of the combustion chamber as a function of the crank angle, $\gamma=\frac{C_{p}}{C_{v}}$ the ratio of the specific heat capacities ( $C_{p}$ and $C_{v}$ ) and $\theta$ the angle. $\mathrm{d} Q_{\text {wall }}$ the rate of heat lossed through the walls. This parameter is obtained from the Equation (2) [18].

$$
\frac{\mathrm{d} Q_{\text {wall }}}{\mathrm{d} \theta}=A \times h \times\left(T-T_{\text {wall }}\right) \times \frac{1}{\omega}
$$

with $A$ gas-wall contact surface, $h$ heat transfer coefficient (in this work, the coefficient used is the one of hohenberg), $T$ the instantaneous gas temperature, $T_{\text {wall }}$ the temperature of the walls and $\omega$ angular speed.

Cyclic dispersion was evaluated using variations in the indicated mean effective pressure for the number of mean samples selected. The coefficient of variation of the indicated mean effective pressure is the most commonly parameter used for a quantitative evaluation of cyclic dispersion [18]. So, this coefficient, 
given by Equation (3), were used in this work [18] [19] [20].

$$
\mathrm{COV}_{\text {IMEP }}=\frac{\operatorname{Std}_{\text {IMEP }}}{\overline{\text { IMEP }}} \times 100
$$

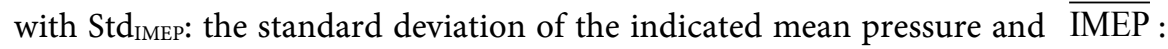
the average indicated mean effective pressure.

\subsection{Formulations}

The formulation consists of mixing different components that do not react with each other and whose purpose is to obtain a final product with particular properties for a given use. The vegetable oil used in this work is Jatropha oil for its availability and it is non-edible. The contents of Jatropha oil retained for the formulations are $70 \%, 80 \%$ and $90 \%$. In fact, the proportions of vegetable oils in blends or emulsions are generally low (less than $40 \%$ ) to ensure proper engine operation [3] [5]. The idea is to reverse the trend by using high contents of Jatropha oil in the formulation so that to get a maximum level of biofuel used. The two other components used are conventional diesel fuel and heptane. Diesel fuel has been chosen because it is the reference fuel in this type of engine. Heptane has been chosen due to the fact that it is generally used as fuel in the modelling of diesel combustion in diesel engines [21]. Furthermore, it has a high cetane number (56) and can therefore be used as a pro-cetane additive to improve the flammability of the mixture. Some work have shown that adding "procetane" fuels up to $8 \%$ to vegetable oils improves their combustion in diesel engines by reducing ignition delay in a similar way to those obtained for diesel fuel [22] [23]. The proportion of heptane in blends ranged from 0 to $10 \%$ in steps of $5 \%$. The different formulations used and their characteristics (determined in this work) are given in Table 3.

\section{Results and Discussion}

\subsection{Results of Engine Performances}

Figures $3(\mathrm{a})-(\mathrm{c})$ present the results of the specific fuel consumption of the engine

Table 3. Different fuels used.

\begin{tabular}{|c|c|c|c|c|c|c|}
\hline & Jatropha oil & $\begin{array}{c}\text { Diesel } \\
\text { fuel }\end{array}$ & Heptane & $\begin{array}{c}\text { Density at } \\
21^{\circ} \mathrm{C}\left(\mathrm{kg} / \mathrm{m}^{3}\right)\end{array}$ & $\begin{array}{c}\text { Viscosity } \\
\text { dynamic (mPa.s) }\end{array}$ & $\begin{array}{c}\mathrm{LVH} \\
(\mathrm{kJ} / \mathrm{kg})\end{array}$ \\
\hline D100 & 0 & $100 \%$ & 0 & 850 & 3.42 & 42,852 \\
\hline J40G60 & $40 \%$ & $60 \%$ & 0 & 875 & 9.25 & 40,084 \\
\hline J70G20H10 & $70 \%$ & $20 \%$ & $10 \%$ & 876 & 15.1 & 38,203 \\
\hline J70G25H5 & $70 \%$ & $25 \%$ & $5 \%$ & & & \\
\hline J80G10H10 & $80 \%$ & $10 \%$ & $10 \%$ & 894 & 16.3 & 37,964 \\
\hline J80G15H5 & $80 \%$ & $15 \%$ & $5 \%$ & & & \\
\hline $\mathrm{J} 90 \mathrm{H} 10$ & $90 \%$ & 0 & $10 \%$ & & & \\
\hline J90G5H5 & $90 \%$ & $5 \%$ & $5 \%$ & & & \\
\hline $\mathrm{J} 100$ & $100 \%$ & 0 & 0 & 917 & 36.9 & 36,974 \\
\hline
\end{tabular}



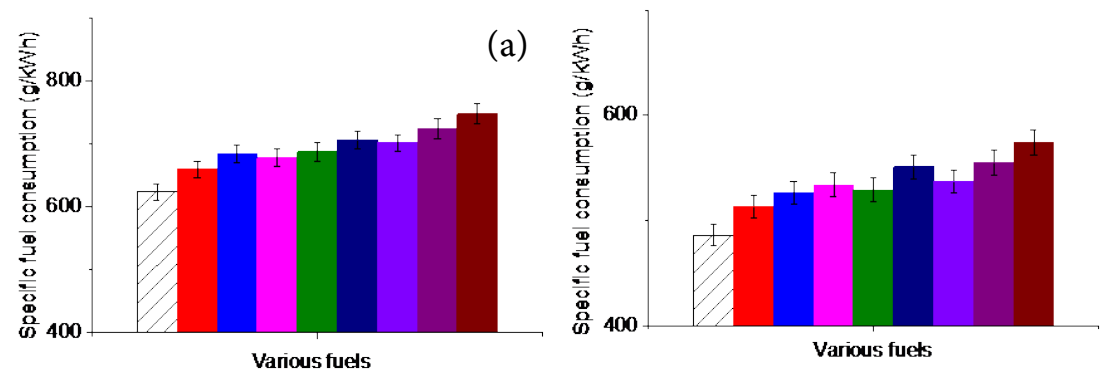

(b)

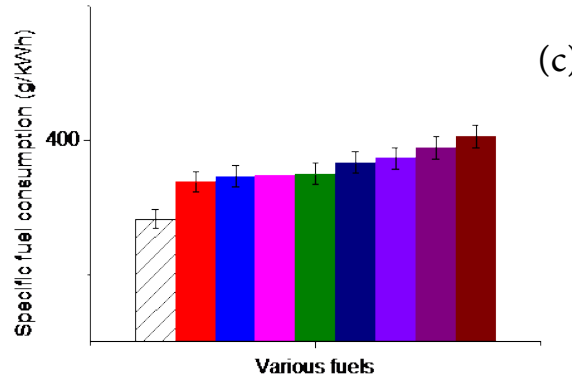

(c)

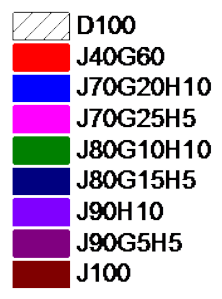

Figure 3. Specific fuel consumption of the engine for the different fuels at the three loads tested: (a) $26 \%$, (b) $43 \%$; (c) $70 \%$.

operating on different fuels at $26 \%, 43 \%$ and $70 \%$ engine loads. Figures 4 (a)-(c) present the results of the overall efficiencies of the engine operating on different fuels at $26 \%, 43 \%$ and $70 \%$ engine loads.

A reduction in the specific fuel consumption of the engine can be noted with the increase in the percentage of heptane in the blends compared to Jatropha oil. In fact, the addition of heptane makes it possible to increase the energy density (LHV) of the blend compared to straight Jatropha oil. Thus, the improved LHV of the blends containing heptane-results in lower specific engine fuel consumption compared to pure Jatropha oil. With blends containing diesel fuel, even if the diesel fuel contributes partly to this reduction, the influence of the heptane contribution remains noticeable. The case of J90H10 (where the reduction in specific fuel consumption compared to vegetable oil is around 7\%) clearly shows the contribution of heptane. Similar results have been observed in previous work [24] [25] [26]. However, the specific fuel consumption of the engine with products containing at least $10 \%$ heptane remains higher than those obtained with diesel fuel (around 10\% - 13\% for the case of J90H10). The blend whose specific fuel consumption is close to that obtained with diesel is J70G20H10.

Comparable thermal efficiencies are observed regardless of the fuel used (diesel, vegetable oil and blends). But it can be observed, when comparing the thermal efficiencies obtained with these different fuels, that the thermal efficiency is improved for blends containing $10 \%$ heptane compared to that of Jatropha oil.

Figures 5(a)-(c) show the engine exhaust gas temperatures for different loads when operating with diesel, vegetable oil and its derivatives.

The influence of heptane on engine exhaust gas temperature can be noted for all the loads studied. Compared to diesel fuel, engine exhaust temperatures are 

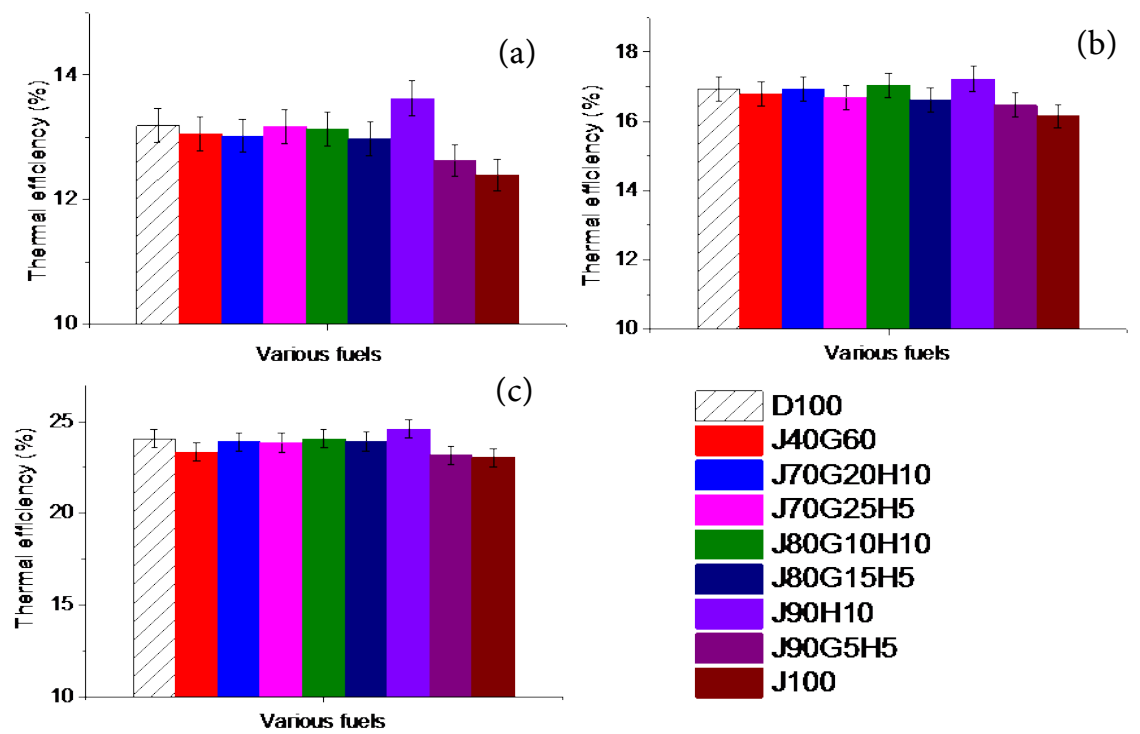

Figure 4. Thermal efficiencies of the engine for the different fuels at the three loads tested: (a) $26 \%$, (b) $43 \%$ and (c) $70 \%$.

(a)

(b)
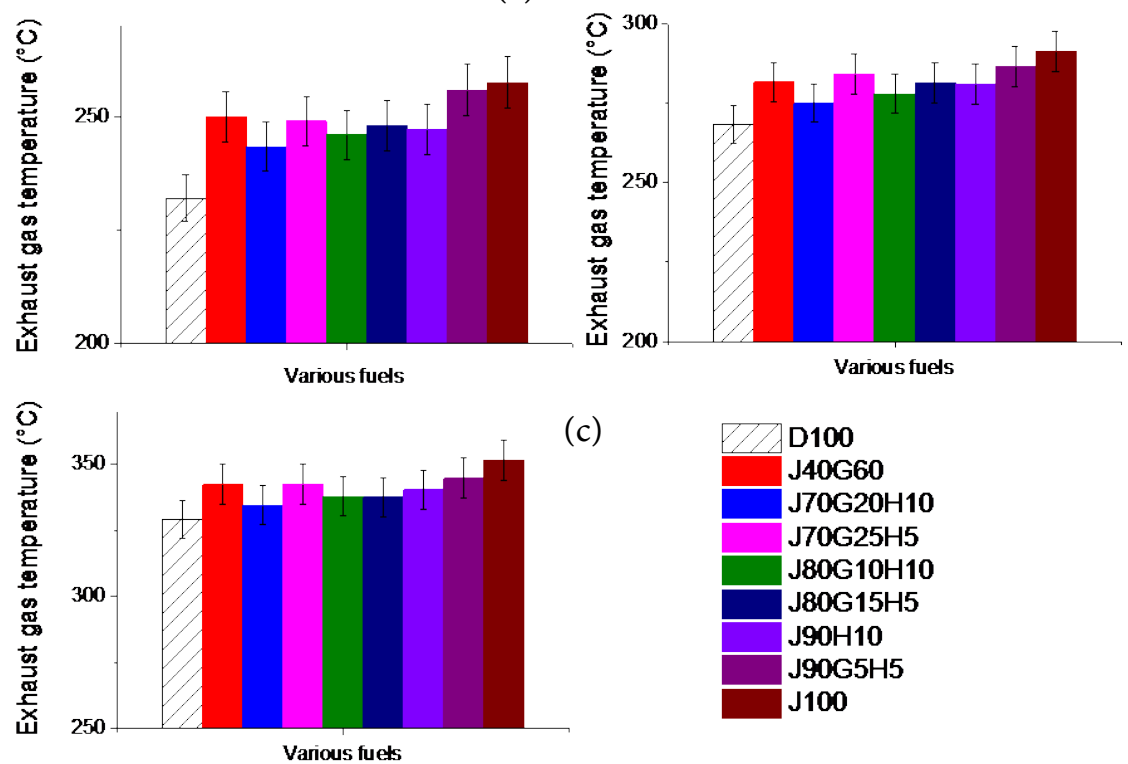

(c)

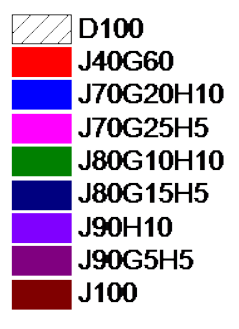

Figure 5. Exhaust gas temperature of the engine for the different fuels at the three loads tested: (a) $26 \%$, (b) $43 \%$ and (c) $70 \%$.

high with blends particularly at low loads (of the order of $5 \%$ to $10 \%$ at $26 \%$ loads applied to the engine).

Using heptane in the formulation results in a slight decrease in engine exhaust gas temperatures compared to those obtained with pure Jatropha oil. However, this drop is not significant in view of the order of magnitude of the uncertainties (of the order of $3 \%$ ), because the addition of relatively small quantities of heptane does not allow significant differences to be observed on a macroscopic parameter such as the exhaust temperature. Nevertheless, one of the blend records 
a relatively interesting decrease in exhaust gas temperature, namely J70G20H10 (6\% for $26 \%$ load applied to the engine). This can be due to the combined effect of heptane and diesel in the formulation allowing a reduction in engine exhaust temperature.

\subsection{Results of Engine Combustion Parameters: Ignition Delay, Heat Release Rate and Cyclic Dispersion}

Figures 6(a)-(c) give the ignition delay of the various fuels for the different engine loads.

The ignition delay values are comparable for all fuels used, but they decrease with increasing load, where the differences become smaller. However, the increase in the heptane fraction in the mixture leads to a slight decrease in the delays. This result could be justified by an improvement in the cetane number of these mixtures when the heptane fraction increases.

A similar result has been found in previous work, using blends containing a cetane improver [23] [27].

Figures 7(a)-(c) show the curves of heat release rate versus crank angle when using the fuels at $26 \%$ engine load.

The heat release rate curves are quite similar regardless of the fuel used. Thus, the three (3) phases of combustion can be noted. The fuel ignition delay phase (heat absorption of the injected droplets), which continues with the kinetic combustion phase (rapid rise in pressure in the combustion chamber) and the diffusing combustion phase. Thus the phenomenology of combustion in this type of engine does not vary according to the fuel. The heat release rate curves are comparable for the different fuels. It can be noted that the kinetic combustion
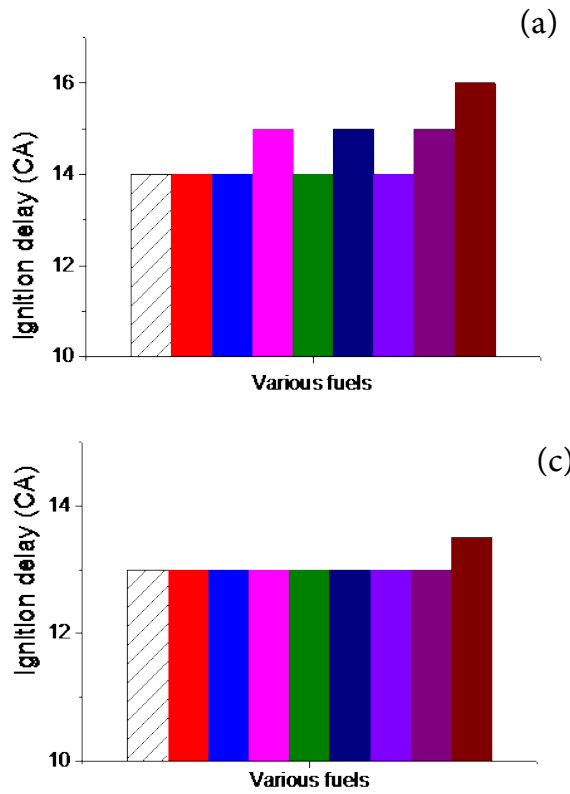

(a)

(c)
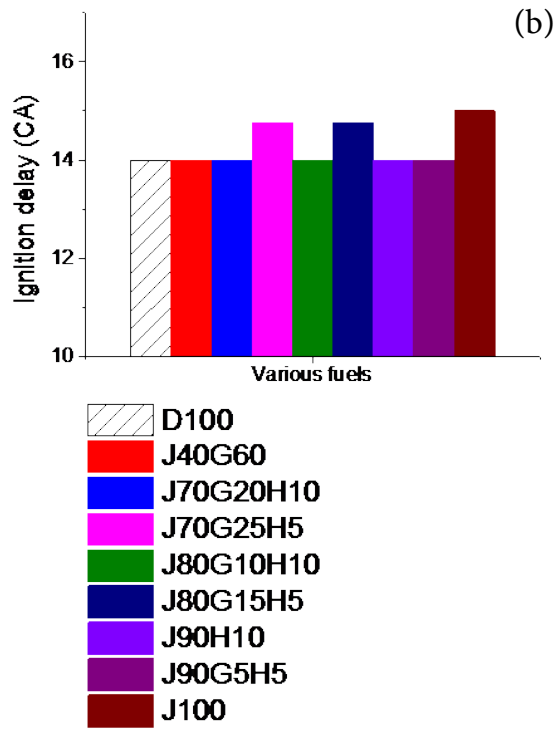

Figure 6. Ignition delay of the different fuels at the three loads tested: (a) $26 \%$, (b) $43 \%$ and (c) $70 \%$. 

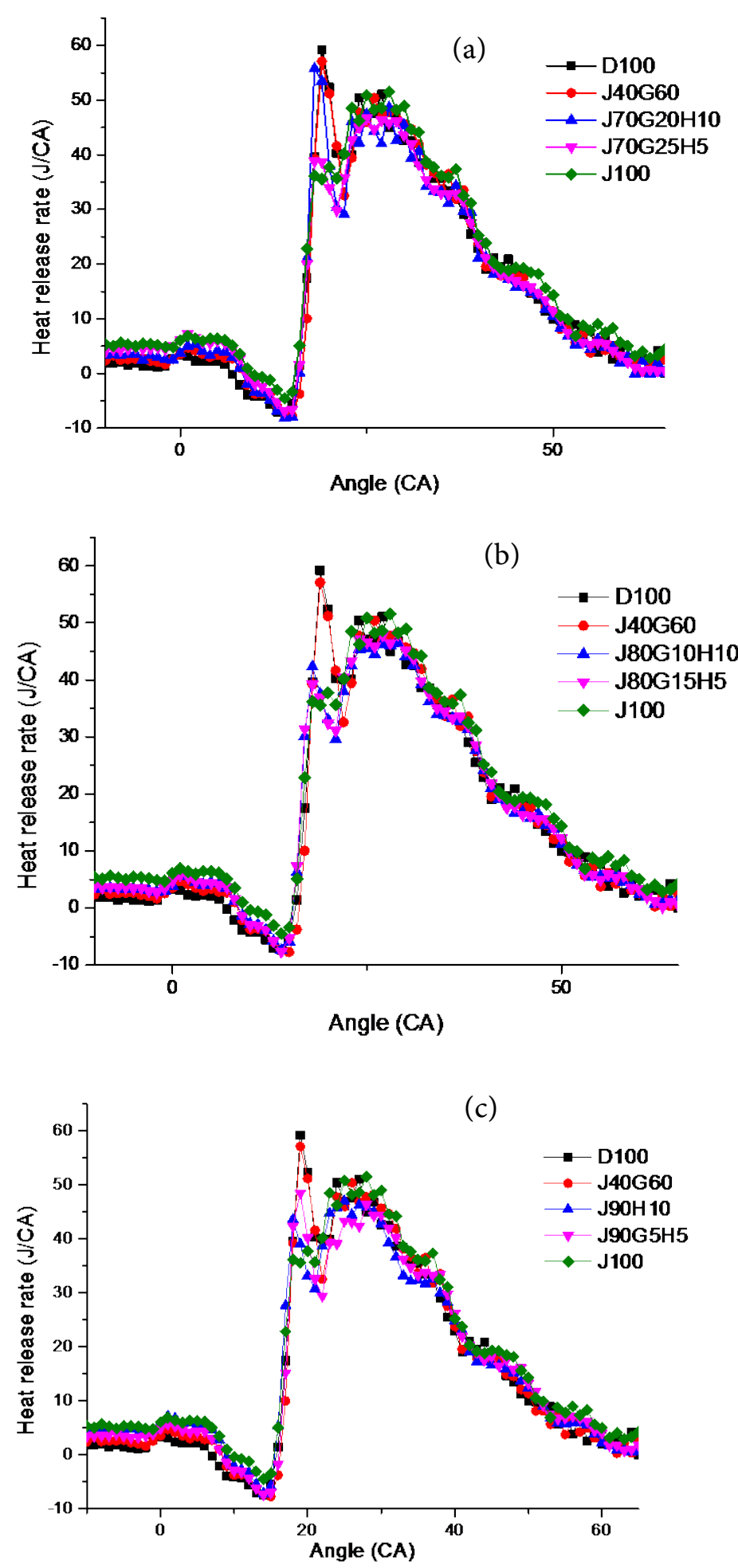

Figure 7. Heat release rate curves as a function of crank angle for different oil contents in the blends: (a) 70\% Jatropha oil, (b) 80\% Jatropha oil and (c) 90\% Jatropha oil.

phase increases relatively with the heptane content in the blend (especially for fuel J70G20H10, which is comparable to that obtained with J40G60 and diesel fuel) compared to that of vegetable oil (Table 4). This increase in the premix 
Table 4. Peak of kinetic combustion and total heat released during the diffusion phase.

\begin{tabular}{ccc}
\hline Fuels & Peak of kinetic combustion $\left(\mathrm{J} /{ }^{\circ} \mathrm{V}\right)$ & $\begin{array}{c}\text { Total heat released during the } \\
\text { diffusion phase }(\mathrm{J})\end{array}$ \\
\hline D & 59.2 & 897.36 \\
J40G60 & 57 & 941.35 \\
J70G20H10 & 55.8 & 894.8 \\
J70G25H5 & 38.8 & 948 \\
J80G10H10 & 42.3 & 956 \\
J80G15H5 & 39.2 & 978.5 \\
J90H10 & 43.6 & 951.1 \\
J90G5H5 & 48.5 & 934.9 \\
J100 & 37.7 & 1092.6 \\
\hline
\end{tabular}

phase is due, on the one hand, to an improvement in the flammability of the mixture (increase in the overall cetane number of the mixture [23] [27]). On the other hand, this is due to an improvement in the fuel spray that is related to a reduction in the viscosity of the blend when both diesel and heptane proportions are increased. The reduction in viscosity of the mixture is $144 \%$ compared to that of Jatropha oil measured at the same temperature. This improves the spray droplets size and their vaporization. As a result, the blend, J70G20H10 vaporizes easily with finer droplets than oil and ignites quickly, giving a higher kinetic peak. Diffusing combustion phases are relatively lower when adding heptane and diesel in the blends compared to those obtained with Jatropha oil (Table 4). This supports the drop obtained in engine exhaust temperature as the heptane and diesel content increases in the formulation.

Figures 8(a)-(c) show the values of the coefficient of variation of the indicated mean effective pressure for all the fuels used at different engine loads.

For all the tests carried out, the combustion cycles are regular because the values of the coefficient of variation of the indicated mean effective pressure do not exceed $10 \%$ for all the loads tested and regardless the fuel used (this limit is set by the literature) [18]. Previous work has shown that combustion in the type of engine used is more stable compared to the direct injection engine [22]. However, depending on the type of fuel, or the load, the differences in cyclic dispersion become more or less important.

The instabilities of engine combustion cycles (cyclic dispersion) decreases with the increase in heptane content in the blend especially at low loads. Engine combustion cycles stability specifically improve with J70G20H10 blend. This could be explained by the combined effect of heptane (10\%) and diesel (20\%) in the blend. Especially for this fuel, the values of the $\mathrm{COV}_{\text {IMEP }}$ are lower compared to those of vegetable oil and similar to those of the J40G60 blend and very close to that of diesel fuel (Figure 8). This blend has a relatively short fuel ignition delay. Indeed, the phenomena that occur during the delay phase (quantity of fuel 


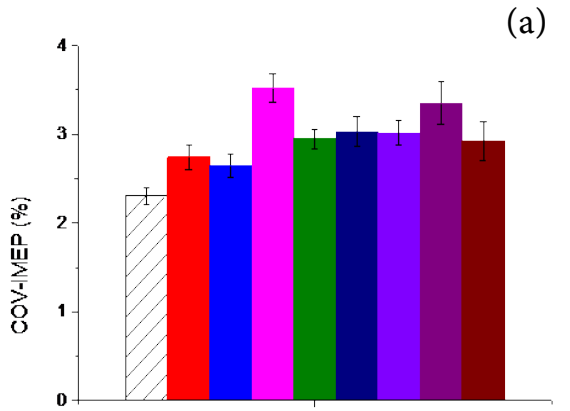

Various fueks

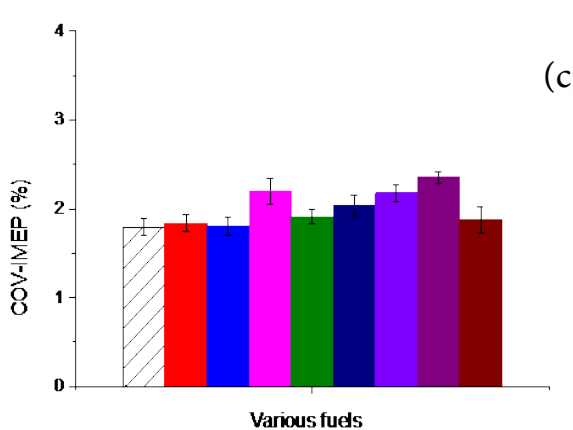

(b)

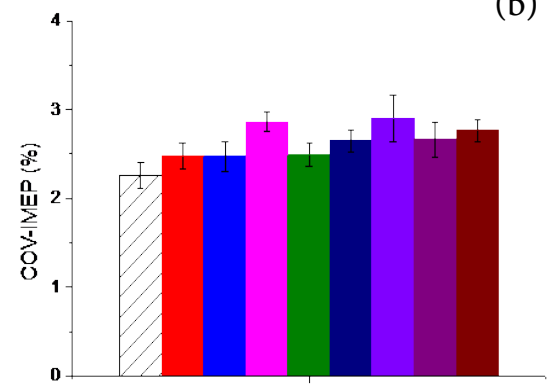

Various fuels

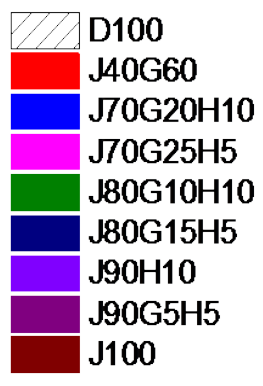

Figure 8. $\mathrm{COV}_{\text {IMEP }}$ for the various fuels at the different engine loads: (a) $26 \%$, (b) $43 \%$ and (c) $70 \%$.

vaporized, quantity and reactivity of the air-fuel premix, etc.) are less repeatable when the fuel ignition delay is long [28] [29] [30].

Previous work has shown that there is a correlation between cyclic dispersion, premix combustion peak and fuel ignition delay extension. However, the high premix is not always a prerequisite for the occurrence of gas fluctuation (or resonance) in the cylinder, other random effects can also induce cycle oscillation [29]. So, even if the premix phase is important with J70G20H10, this seems to have limited effect on the stability its combustion. The results obtained for cyclic dispersion are consistent with the engine performance results, i.e., fuels that lead to instabilities in the combustion cycle also lead to a deterioration in engine performance. The differences in cycles stability are small for all fuels tested at high load. This is consistent with the results of previous studies on the tendency of vegetable oils, their derivatives and diesel fuel (delays, evaporation constants, etc.) to have a single behavior due to the high temperature levels favorable to the degradation of all the products formed during the combustion process [5] [14].

These observations reflect the improvement in the flammability of the mixture with heptane (10\% proportion) and consequently the improvement and regularity of the cycles.

Figure 9 show a multi-criteria diagram of variations in engine parameters with the various blends compared to those obtained with pure Jatropha oil at $26 \%$ of load.

By comparing the variations in engine parameters using formulations, compared to pure Jatropha oil, the blend J70G20H10 stands out. The engine operating 


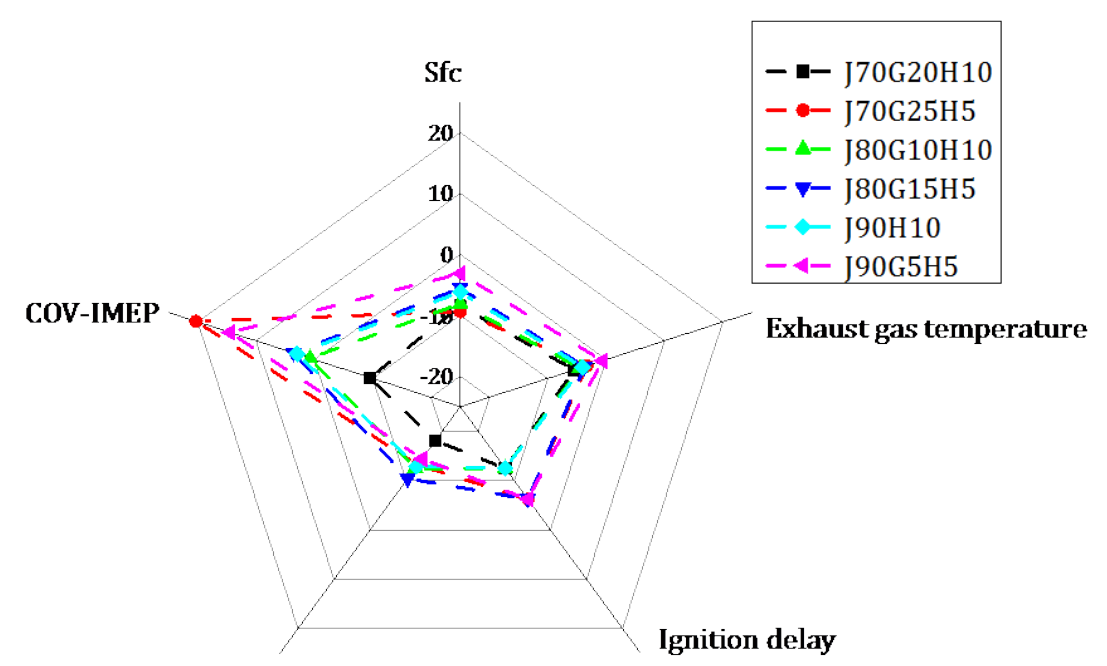

Total heat released during the diffusion phase

Figure 9. Multi-criteria diagram of variations in engine parameters with the various blends compared to those obtained with pure Jatropha oil.

on it shows a significant improvement in the parameters considered compared to pure Jatropha oil and the other blends.

\section{Conclusions}

The aim of this work was to determine blends from Jatropha oil, diesel fuel and heptane with improved combustion conditions in the engine. Analysis of engine performance, combustion parameters and particularly cyclic dispersion shows that:

- Increasing the heptane content in the blends improves its energy density and leads to a reduction in the specific fuel consumption of the engine compared to that obtained with pure vegetable oil. This specific fuel consumption of the engine is close to that obtained with diesel. This improvement in specific engine fuel consumption is greatest for J70G20H10; however, the overall efficiencies of the engine operating on all the blends are very close to those obtained with diesel.

- Engine exhaust gas temperatures decrease relatively as the heptane content in the blends increases.

- The influence of the heptane content in the blends on the ignition delay is relatively small. There is a slight decrease in fuel ignition delays as the heptane content increases in the blends.

- The flammability of blends is improved with the proportion of heptane in the mixture. This is shown by significant kinetic peaks compared to the results obtained with pure Jatropha oil. It should also be noted that the kinetic combustion peaks are similar to those obtained with diesel.

- Cyclic dispersion is less important when the heptane content in the blend is around $10 \%$. For formulations based on Jatropha oil, diesel fuel and heptane, the best results are obtained with J70G20H10 fuel. 
Globally, the results show that the use of Jatropha oil, blended with diesel fuel and heptane is relevant to improves the combustion of Jatropha oil. Further investigation on the engine emissions and carbon deposits, when using the various blends tested, is needed for better assessment of the relevance.

\section{Acknowledgements}

The authors would like to thank the "Union Economique et Monétaire Ouest Africaine (UEMOA)" for its support in the acquisition and the implementation of the engine test bench.

\section{Conflicts of Interest}

The authors declare no conflicts of interest regarding the publication of this paper.

\section{References}

[1] Carbonnier, G. and Jacques, G. (2011) Energie et développement. International Development Policy, 2, 9-28. https://doi.org/10.4000/poldev.687

[2] Blimpo, M.P. and Cosgrove-Davies, M. (2019) Electricity Access in Sub-Saharan Africa Uptake, Reliability, and Complementary Factors for Economic Impact. World Bank, Washington DC. https://doi.org/10.1596/978-1-4648-1361-0

[3] Sidibe, S., Blin, J., Daho, T., Vaitilingom, G. and Koulidiati, J. (2020) Comparative Study of Three Ways of Using Jatropha curcas Vegetable Oil in a Direct Injection Diesel Engine. Scientific African, 7, 290-308. https://doi.org/10.1016/j.sciaf.2020.e00290

[4] Daho, T., Vaitilingom, G. and Sanogo, O. (2009) Optimization of the Combustion of Blends of Domestic Fuel Oil and Cottonseed Oil in a Non-Modified Domestic Boiler. Fuel, 88, 1261-1268. https://doi.org/10.1016/j.fuel.2008.12.021

[5] Daho, T., Vaitilingom, G., Ouiminga, K.S., Piriou, B., Zongo, S.A., Ouoba, S. and Koulidiati, J. (2013) Influence of Engine Load and Fuel Droplet Size on Performance of a CI Engine Fueled with Cottonseed Oil and Its Blends with Diesel Fuel. Applied Energy, 111, 1046-1053. https://doi.org/10.1016/j.apenergy.2013.05.059

[6] Daho, T., Vaitilingom, G., Sanogo, O., Ouiminga, S.K., Segda, B.G., Valette, J., Higelin, P. and Koulidiati, J. (2012) Model for Predicting Evaporation Characteristics of Vegetable Oils Droplets Based on Their Fatty Acid Composition. International Journal of Heat and Mass Transfer, 55, 2864-2871. https://doi.org/10.1016/j.ijheatmasstransfer.2012.01.048

[7] Zongo, A.S., Daho, T., Vaitilingom, G., Piriou, B., Valette, J., Caillol, C., Segda, B.G., Higelin, P. and Koulidiati, J. (2018) The Effect of Atmospheric Oxygen on the Puffing and Bursting Phenomena during Vegetable Oils Droplets Vaporization Process for Their Use as Biofuel in Diesel Engine. Energy and Power Engineering, 10, 518533. https://doi.org/10.4236/epe.2018.1012033

[8] Basinger, M., Reding, T., Williams, C., Lackner, K.S. and Modi, V. (2010) Compression Ignition Engine Modifications for Straight Plant Oil Fueling in Remote Contexts: Modification Design and Short-Run Testing. Fuel, 89, 2925-2938. https://doi.org/10.1016/j.fuel.2010.04.028

[9] Atmanli, A., Ileri, E., Yuksel, B. and Yilmaz, N. (2015) Extensive Analyses of DieselVegetable Oil-n-Butanol Ternary Blends in a Diesel Engine. Applied Energy, 145, 
155-162. https://doi.org/10.1016/j.apenergy.2015.01.071

[10] Yilmaz, N., Atmanli, A. and Trujillo, M. (2017) Influence of 1-Pentanol Additive on the Performance of a Diesel Engine Fueled with Waste Oil Methyl Ester and Diesel Fuel. Fuel, 207, 461-469. https://doi.org/10.1016/j.fuel.2017.06.093

[11] Yilmaz, N. and Morton, B. (2011) Effects of Preheating Vegetable Oils on Performance and Emission Characteristics of Two Diesel Engines. Biomass and Bioenergy, 35, 2028-2033. https://doi.org/10.1016/j.biombioe.2011.01.052

[12] Ramadhas, A.S., Jayaraj, S. and Muraleedharan, C. (2005) Characterization and Effect of Using Rubber Seed Oil as Fuel in the Compression Ignition Engines. Renewable Energy, 30, 795-803. https://doi.org/10.1016/j.renene.2004.07.002

[13] Kalam, M.A. and Masjuki, H.H. (2004) Emissions and Deposit Characteristics of a Small Diesel Engine When Operated on Preheated Crude Palm Oil. Biomass and Bioenergy, 27, 289-297. https://doi.org/10.1016/j.biombioe.2004.01.009

[14] Daho, T., Vaitilingom, G., Sanogo, O., Ouiminga, S.K., Segda, B.G., Valette, J., Higelin, P. and Koulidiati, J. (2012) Study of Droplet Vaporization of Various Vegetable Oils and Blends of Domestic Fuel Oil-Cottonseed Oil under Different Ambient Temperature Conditions. Biomass and Bioenergy, 46, 653-663. https://doi.org/10.1016/j.biombioe.2012.06.031

[15] Zongo, A.S. (2015) Etude des processus physiques et chimiques mis en jeu lors de la combustion des huiles végétales pures dans les moteurs diesels: Mécanismes de décomposition et de polymérisation. PhD Thesis, Université d'Orléans et Université de Ouagadougou.

[16] Roy, M.M., Wilson, W. and Da Silva, A.F.G. (2015) Effect of n-Heptane on Cold Flow Properties of Biodiesel Blends and Performance of a DI Diesel Engine. International Journal of Mechanical and Mechatronics Engineering, 15, 1-10.

[17] Agarwal, D. and Agarwal, A.K. (2007) Performance and Emissions Characteristics of Jatropha Oil (Preheated and Blends) in a Direct Injection Compression Ignition Engine. Applied Thermal Engineering, 27, 2314-2323. https://doi.org/10.1016/j.applthermaleng.2007.01.009

[18] Heywood, J.B. (1988) Internal Combustion Engine Fundementals. Vol. 21. United States of America.

[19] Wang, Y., Xiao, F., Zhao, Y., Li, D. and Lei, X. (2015) Study on Cycle-by-Cycle Variations in a Diesel Engine with Dimethyl Ether as Port Premixing Fuel. Applied Ener$g y$, 143, 58-70. https://doi.org/10.1016/j.apenergy.2014.12.079

[20] Chen, Z., Yao, C., Yao, A., Dou, Z., Wang, B., Wei, H., Liu, M., Chen, C. and Shi, J. (2017) The Impact of Methanol Injecting Position on Cylinder-to-Cylinder Variation in a Diesel Methanol Dual Fuel Engine. Fuel, 191, 150-163. https://doi.org/10.1016/j.fuel.2016.11.072

[21] Ganquin, M. (2013) Modélisation 1d de la combustion diesel application a un moteur automobile. PhD Thesis, Ecole centrale de Nantes, Université Nantes Angers Le Mans.

[22] Satgé De Caro, P., Mouloungui, Z., Vaitilingom, G. and Berge, J.C. (2001) Interest of Combining an Additive with Diesel-Ethanol Blends for Use in Diesel Engines. Fuel, 80, 565-574. https://doi.org/10.1016/S0016-2361(00)00117-4

[23] Gilles, V., Philipe, H., Andrzejewski, J. and Sapinski, A. (1991) Influence du nitrate d'hexyle et de la température de l'air admis sur les délais d'inflammation des huiles végétales dans un moteur diesel. Entropie, 161, 39-43.

[24] Ileri, E. (2016) Experimental Study of 2-Ethylhexyl Nitrate Effects on Engine Performance and Exhaust Emissions of a Diesel Engine Fueled with n-Butanol or 1-Pen- 
tanol Diesel-Sunflower Oil Blends. Energy Conversion and Management, 118, 320 330. https://doi.org/10.1016/j.enconman.2016.04.015

[25] Atmanli, A. (2016) Effects of a Cetane Improver on Fuel Properties and Engine Characteristics of a Diesel Engine Fueled with the Blends of Diesel, Hazelnut Oil and Higher Carbon Alcohol. Fuel, 172, 209-217.

https://doi.org/10.1016/j.fuel.2016.01.013

[26] Vallinayagam, R., Vedharaj, S., Yang, W.M., Saravanan, C.G., Lee, P.S., Chua, K.J.E. and Chou, S.K. (2014) Impact of Ignition Promoting Additives on the Characteristics of a Diesel Engine Powered by Pine Oil-Diesel Blend. Fuel, 117, 278-285. https://doi.org/10.1016/j.fuel.2013.09.076

[27] Venkateswarlu, K., Ramakrishna, K. and Vijaya Kumar, K. (2012) Improvement of Engine Performance and Emissions with Ethyl Hexyl Nitrate and Diesel-Biodiesel Blends. International Energy Journal, 13, 85-96.

[28] Rakopoulos, D.C., Rakopoulos, C.D., Giakoumis, E.G., Komninos, N.P., Kosmadakis, G.M. and Papagiannakis, R.G. (2016) Comparative Evaluation of Ethanol, n-Butanol, and Diethyl Ether Effects as Biofuel Supplements on Combustion Characteristics, Cyclic Variations, and Emissions Balance in Light-Duty Diesel Engine. Journal of Energy Engineering, 143, Article ID: 04016044. https://doi.org/10.1061/(ASCE)EY.1943-7897.0000399

[29] Kyrtatos, P., Brückner, C. and Boulouchos, K. (2016) Cycle-to-Cycle Variations in Diesel Engines. Applied Energy, 171, 120-132.

https://doi.org/10.1016/j.apenergy.2016.03.015

[30] Kyrtatos, P., Hoyer, K., Obrecht, P. and Boulouchos, K. (2014) Apparent Effects of In-Cylinder Pressure Oscillations and Cycle-to-Cycle Variability on Heat Release Rate and Soot Concentration under Long Ignition Delay Conditions in Diesel Engines. International Journal of Engine Research, 15, 325-337. https://doi.org/10.1177/1468087413483288

\section{Abbreviations}

\begin{tabular}{cc}
\hline CA & Crank Angle \\
COV & Coefficient Of Variation \\
IMEP & Indicate Mean Effective Pressure \\
LHV & Lower Heating Value \\
SfC & Specific fuel consumption \\
\hline
\end{tabular}

